\title{
Methods for genomic characterization and maintenance of anaerobic fungi
}

\author{
by Peng, X, Swift, C.L., Theodorou, M.K. and O'Malley, \\ M.A.
}

Copyright, publisher and additional information: This is the author accepted manuscript of a book chapter. The final published version (version of record) is published by SpringerLink in the book Fungal genomics: methods and protocols

https://link.springer.com/protocol/10.1007\%2F978-1-4939-7804-5 5

Please refer to any applicable terms of use of the publisher. 


\section{Methods for Genomic Characterization and Maintenance of Anaerobic Fungi}

Xuefeng Peng ${ }^{1}$, Candice L. Swift ${ }^{1}$, Michael K. Theodorou ${ }^{2}$, and Michelle A. O’Malley ${ }^{1 \ddagger}$

${ }^{1}$ Department of Chemical Engineering, University of California, Santa Barbara, CA 93106, USA

${ }^{2}$ Animal Production, Welfare and Veterinary Sciences, Harper Adams University, Newport, Shropshire, TF10 8NB, UK

‡ Corresponding Author. E-mail: momalley@engineering.ucsb.edu

Running title: Anaerobic Fungi Genomic Characterization and Maintenance

\section{Abstract (100 word limit)}

The rapid development of molecular biology and bioinformatics has fueled renewed interests in anaerobic fungi from the phylum Neocallimastigomycota. This chapter presents well-established methods for isolation, routine cultivation, and cryo-preservation of anaerobic fungi. Moreover, detailed nucleic acid extraction protocols are provided, which should enable readers to isolate high quality DNA and RNA from a variety of anaerobic fungal culture media for downstream applications such as next-generation sequencing.

Keywords: Anaerobic fungi, Genomes, Transcriptomes, DNA extraction, RNA extraction, cultivation, isolation, Neocallimastigomycota, next-generation sequencing, consecutive batch culture 


\section{$1 \quad$ Introduction}

Since the discovery of chitin in the cell wall of Neocallimastigomycota [1], which led to their reclassification from protozoa to fungi, there has been a large body of published literature that describes their morphology, physiology, ecology, and biochemistry [2]. The rapid development of molecular biology and bioinformatics in the past decade has provided powerful tools for scientists and engineers to gain deeper insight into the functional role of these unusual anaerobic fungi.

In particular, next-generation sequencing approaches have opened the way for comparative genomics, transcriptomics, and metagenomic modeling in these systems for the first time [3]. For example, a recent study identified novel enzyme candidates in anaerobic fungi for lignocellulose breakdown by combining transcriptomics, proteomics, and biochemical characterization [4], which are a powerful combination of tools that also promise to unravel the native syntrophy of anaerobic fungi and methanogenic archaea [5]. All of these methods depend upon successful cultivation of the anaerobic fungi and effective extraction of high-quality nucleic acid samples. This chapter builds upon established methods for basic maintenance of anaerobic fungi, and highlights new protocols we have developed in the laboratory to extract high molecular weight genomic DNA, as well as intact RNA for next-generation sequencing applications. We also include helpful tips for troubleshooting these experiments that are not easily found in the literature.

The first part of the methods discussed pertains to routine isolation and maintenance of anaerobic fungi based on the consecutive batch culture technique [6]. We then provide detailed protocols for extraction of RNA from batch cultures of anaerobic fungi or mixed microbial consortia that also include prokaryotic organisms (bacteria and archaea). Finally, we focus on two effective cell disruption methods to rapidly isolate high-quality genomic DNA from anaerobic fungi, which relies on simple-to-implement commercial kits. 


\section{Materials}

\subsection{For routine cultivation}

1. Clarified rumen fluid: fresh rumen fluid centrifuged at $3220 \mathrm{~g}$ (or sufficient speed to sediment all particles, leaving a tan or greenish colored clarified liquid) for 1 hour at $4^{\circ} \mathrm{C}$, separated from the resulting cell pellet. Carefully transfer $75 \mathrm{ml}$ of the supernatant into 120 $\mathrm{ml}$ serum bottles and store at $-20^{\circ} \mathrm{C}$. Volumes of one liter to three liters are routinely clarified at one time.

2. Double clarified rumen fluid: autoclave the clarified rumen fluid at $121^{\circ} \mathrm{C}$ for 40 min and store at $4^{\circ} \mathrm{C}$. Before use, the autoclaved rumen fluid is centrifuged at $3220 \mathrm{~g}$ (or sufficient speed to sediment all particles, leaving a tan or greenish colored clarified liquid) for $30 \mathrm{~min}$ at $4^{\circ} \mathrm{C}$. Only use the resulting supernatant for subsequent media making.

3. Mineral Solution I: Dissolve $3.0 \mathrm{~g}$ of dibasic potassium phosphate $\left(\mathrm{K}_{2} \mathrm{HPO}_{4}\right)$ in $1 \mathrm{~L}$ of water. Filter sterilize and store at $4^{\circ} \mathrm{C}$.

4. Mineral Solution II: Dissolve $3.0 \mathrm{~g}$ of monobasic potassium phosphate $\left(\mathrm{KH}_{2} \mathrm{PO}_{4}\right), 6.0 \mathrm{~g}$ of ammonium sulfate $\left(\left(\mathrm{NH}_{4}\right)_{2} \mathrm{SO}_{4}\right), 6.0 \mathrm{~g}$ of sodium chloride $(\mathrm{NaCl})$, and $0.6 \mathrm{~g}$ of magnesium sulfate heptahydrate $\left(\mathrm{MgSO}_{4} .7 \mathrm{H}_{2} \mathrm{O}\right)$ in $800 \mathrm{ml}$ of water. Dissolve $0.6 \mathrm{~g}$ of calcium chloride dihydrate $\left(\mathrm{CaCl}_{2} .2 \mathrm{H}_{2} \mathrm{O}\right)$ in $100 \mathrm{ml}$ of water separately. These two solutions are combined, filter sterilized, and made up to a final volume of $1 \mathrm{~L}$ with water. Store at $4{ }^{\circ} \mathrm{C}$.

5. Resazurin stock solution $(1 \mathrm{mg} / \mathrm{ml})$ : Dissolve $0.100 \mathrm{~g}$ of resazurin sodium salt (redox indicator) in $100 \mathrm{ml}$ of water and filter sterilize. Store at $4{ }^{\circ} \mathrm{C}$.

6. Chloramphenicol stock solution $(10 \mathrm{mg} / \mathrm{ml})$ : First completely dissolve $0.50 \mathrm{~g}$ of chloramphenicol (C1863 Sigma) in minimal amount of molecular biology grade ethanol (20 
$\mathrm{ml}$ or less). Add water to a final volume of $50 \mathrm{ml}$. Filter sterilize the solution and store at $4^{\circ} \mathrm{C}$.

7. Sodium bicarbonate, yeast extract, and Bacto $^{\mathrm{TM}}$ Casitone (or tripticase peptone).

8. $\quad$ Plant material: should be air dry and milled to provide millimeter-sized pieces (generally 2$4 \mathrm{~mm}$ ). Some examples include reed canary grass, switchgrass, alfalfa stems, and corn stover.

9. A static incubator set at $39^{\circ} \mathrm{C}$, weighing boats, spatulas, beakers, graduated cylinders, 2-L microwave flask (must fit in a microwave), carbon dioxide $\left(\mathrm{CO}_{2}\right)$, gas manifolds to distribute $\mathrm{CO}_{2}$, pipettes, 5-mL syringes connected to blunt-end needles, and autoclave are also required. Hungate tubes with butyl rubber stoppers and/or serum bottles outfitted with butyl rubber stoppers and crimp seals are adequate vessels for culturing the anaerobic fungi. It is also advantageous to have access to a pressure transducer manifold for quantifying fungal growth $[7]$.

\subsection{For nucleic acid (DNA/RNA) extraction}

1. Biospec Mini-Beadbeater-16

2. Gel-loading pipet tips

3. 2-ml screw-cap tubes and caps with O-ring

4. $\quad 0.5 \mathrm{~mm}$ zirconia/silica beads (Biospec)

5. Microcentrifuge

6. Vortexer

7. RNAlater

8. Centrifuge 


\section{Methods}

\subsection{Media preparation}

Anaerobic media is required for isolation and maintenance of anaerobic fungi as detailed in this section. Many of the recipes and culture techniques used in rumen microbiology were first described by Hungate [8], followed by a number of modifications [9-11]. Liquid media is typical for routine maintenance; media supplemented with agar $(1 \% \mathrm{w} / \mathrm{v})$ for solidification in roll tubes are often used for fungal isolation procedures.

The following is a recipe for preparing 1 liter of Medium C (use amounts shown in Table 1) or "Medium C Minus" ("MC-", use amounts shown in Table 2; see Note 1) dispensed in 9-ml aliquots. Alternatively, media can also be dispensed in larger volumes into serum bottles with crimp seals. All media should be prepared and aliquoted under a stream of $\mathrm{CO}_{2}$ to minimize the introduction of oxygen.

1. Weigh out yeast extract, Bacto ${ }^{\mathrm{TM}}$ Casitone, and sodium bicarbonate into a 2-L flask.

2. Add $150 \mathrm{ml}$ of Mineral Solutions I and II, and clarified rumen fluid.

3. Microwave for 20 minutes (see Note 2).

4. Purge with $\mathrm{CO}_{2}$ for 10 minutes (see Notes 3 - 4).

5. Transfer into a 1-L bottle with $1 \mathrm{~g}$ of cysteine in it.

6. Close the lid and let it cool to below $39^{\circ} \mathrm{C}$. (Optional: To speed up the cooling, place the media bottle into an ice bath.)

7. Dispense $9 \mathrm{ml}$ of media into $16-\mathrm{ml}$ Hungate tubes with substrates pre-weighed and aliquoted in them. For roll tubes, dispense $5 \mathrm{ml}$ of media into $20-\mathrm{ml}$ Balch tubes with 1\%(w/v) agar pre-weighed in them. a) Use a 3-way gas manifold for $\mathrm{CO}_{2}$ supply during media dispensing 
(Figure 1). One of them is placed in the media bottle, and the other two are placed in Hungate tubes. Use blunt-end needles (14 gauge, 6 inches long, Cadence Inc.) at the end of the manifold. For the two needles purging Hungate tubes, bend the ends at about 1 inch length, so that they are not directly blowing at the carbon substrate at the bottom of the Hungate tubes. a) Use a 10-ml serological pipet to dispense $9 \mathrm{ml}$ of media into a Hungate while it is purged with $\mathrm{CO}_{2}$. c) Place a septum to cover the top of the Hungate tube, and cover it completely as the blunt-end needle is pulled out of this Hungate tube and placed into another one. Perform this step carefully to minimize introducing any air into the headspace of the Hungate tube. d) Seal the Hungate tube with a plastic screw cap (see Note 5).

8. Sterilize by autoclaving.

9. Liquid media are ready for use after they are pre-warmed to $39^{\circ} \mathrm{C}$. Roll tubes are prepared by melting the solid media with agar $(1 \% \mathrm{w} / \mathrm{v})$ in boiling water and allowing tubes to cool in a water bath at $55^{\circ} \mathrm{C}$. Roll the tubes under a cold water stream to evenly distribute a thin layer of solid media on the inner wall of Balch tubes (see Note 6).

\subsection{Isolation of anaerobic fungi}

Multiple methods have been used to isolate anaerobic gut fungi from rumen digesta and fecal materials, such as those published by Orpin 1975 [12], Bauchop and Mountfort 1981 [13], Lowe et al. 1985 [14], Joblin 1981 [15]. Here, we describe a straightforward method for isolating anaerobic fungi starting from the fresh fecal materials of large mammalian herbivores, but these methods can be readily adapted to isolate fungi from other sources.

1. Prepare Medium $\mathrm{C}$ without plant substrates and Medium $\mathrm{C}$ with reed canary grass (or another lignocellulosic substrate). Include chloramphenicol in these media with a final concentration of $0.1 \mathrm{mg} / \mathrm{ml}$ in the media. 
2. Collect fresh fecal material and transport to laboratory facilities (keep as anaerobic as possible).

3. Prepare the initial inoculum by physically breaking down fecal material and transferring them into Medium $\mathrm{C}$ without plant substrates under a stream of $\mathrm{CO}_{2}$. The final concentration of fecal material in Medium C should be approximately $10 \% \mathrm{w} / \mathrm{v}$.

4. Using a wide-bore needle (0.2 mm or larger) and syringe, prepare 1:10, 1:100, and 1:1000 dilution of the initial inoculum with Medium $\mathrm{C}$ without plant substrates.

5. Inoculate Medium $\mathrm{C}$ containing reed canary grass with the initial inoculum and the three serial dilutions, with a final inoculum concentration of $10 \% \mathrm{v} / \mathrm{v}$. Inoculate three to five replicate tubes for each dilution.

6. Examine growth daily and select enrichment cultures from tubes which show fungal growth. Fungal growth is easily observed by "bubbling" of the grass substrate and/or floating of the grass substrate within the culture tube.

7. Inoculate and evenly distribute $0.1 \mathrm{ml}$ of selected liquid cultures into each roll tube.

8. Examine the growth of fungal colonies over time and select at least three colonies.

9. Under a $\mathrm{CO}_{2}$ stream, pick the selected fungal colonies and inoculate them into liquid media supplemented with chloramphenicol.

10. To ensure axenic cultures are obtained, repeat Steps $6-9$ at least twice more.

11. Putative axenic cultures should be examined using microscopy, and their phylogeny can be determined by sequencing their ITS region [16].

\subsection{Maintenance of anaerobic fungi}

Once axenic cultures of anaerobic fungi have been established, they are easily maintained in small batch cultures prepared in gas-tight glass vessels (as detailed in the "Media Preparation" section). 
These fungal cultures reach exponential phase of growth typically three to four days after inoculation, and are ready to be transferred into fresh medium. The following procedure adapted from Theodorou and colleagues [17] is used for transferring growing fungal cultures into fresh medium.

1. Flame the rubber stoppers of both the inoculum culture and the fresh tube to be inoculated with $100 \%$ ethanol.

2. Shake the inoculum culture vigorously to disperse the fungal material.

3. Invert the tube and insert a needle with syringe into the tube and withdraw $1 \mathrm{ml}$. If the needle is clogged by particles, try clearing the clog by pushing the plunger gently up and down.

4. Inject the $1 \mathrm{ml}$ inoculum into the recipient tube with $9 \mathrm{ml}$ of fresh medium. Invert the recipient tube several times.

5. Incubate cultures at $39^{\circ} \mathrm{C}$.

\subsection{Cryo-preservation of anaerobic fungi}

For long-term maintenance of anaerobic fungi, cultures are flash-frozen in liquid nitrogen and stored at $-80^{\circ} \mathrm{C}$ using glycerol as a cryoprotectant. The following procedure is based on the method published by Solomon et al. [18].

1. Prepare Medium C containing 15\% glycerol (Table 1). This solution should be as anaerobic as possible.

2. Grow fungal culture in Medium $\mathrm{C}$ for three to four days with excess plant substrate $(3 \% \mathrm{w} / \mathrm{v})$ in Hungate tubes.

3. Using a syringe and needle, remove all liquid $(\sim 10 \mathrm{ml})$ in the culture. 
4. Inject $10 \mathrm{ml}$ of Medium C containing $15 \%$ glycerol into the Hungate tube with the residual plant substrate. Shake gently to mix well.

5. Open the Hungate tube under a stream of $\mathrm{CO}_{2}$. Using pipet tips with tips cut off, transfer 1.8 $\mathrm{ml}$ into $2 \mathrm{ml}$ screw-top cryovials.

6. Immediately freeze in liquid nitrogen and store at $-80^{\circ} \mathrm{C}$.

\subsection{Reviving cryo-preserved fungal stocks}

1. Thaw cryo-preserved fungal stocks at $39^{\circ} \mathrm{C}$.

2. Under $\mathrm{CO}_{2}$ streams, or in an anaerobic chamber, remove the liquid media containing $15 \%$ glycerol. Leave the plant material behind.

3. Transfer $1 \mathrm{ml}$ of fresh medium into the cryo-vial.

4. Use cutoff pipet tips to transfer the re-suspended culture into a pre-warmed culture tube.

5. Add chloramphenicol to prevent bacterial contamination (final concentration $0.1 \mathrm{mg} / \mathrm{ml}$ ).

6. Incubate at $39^{\circ} \mathrm{C}$ and check the growth of the culture daily.

\subsection{Determining growth curves using a pressure transducer}

It is often necessary to determine the relative stage of growth of anaerobic fungal cultures depending to assist in experimental design and analysis. However, due to the heterogeneity, filamentous nature, and intimate association with plant biomass particles, it is not possible to determine their growth by monitoring the optical density of fungal cultures. Alternatively, measuring the pressure in the headspace of the culture tubes/serum bottles provides a straightforward approximation of the growth of anaerobic fungi, because fermentation gases 
(predominantly $\mathrm{CO}_{2}$ and $\mathrm{H}_{2}$ ) accumulate as a consequence of growth. This inexpensive and nondestructive method [19] requires a simple pressure transducer (Figure 2), and is described below. All pressure measurements should be performed at $39^{\circ} \mathrm{C}$ due to pressure sensitivity to temperature fluctuations. Before introducing a needle into a sample tube/bottle, the rubber stopper is typically sterilized by flaming.

1. Immediately after inoculating a fresh medium tube, release excess pressure in the headspace so that the headspace pressure equals atmospheric pressure on the pressure gauge.

2. Every six to eight hours, measure, record, and release the headspace pressure.

3. Plot accumulated pressure against time. It generally takes at least six days to reach stationary phase (Figure 3).

\subsection{Preparation of RNA}

Perform protocol using standard best practices for an RNase-free environment (see Note 7).

1. Invert the culturing vessel (Hungate tubes or serum bottles) several times to break apart the plant substrate with fungal mat.

2. Transfer the culture media including the plant substrate into centrifuge tubes (15-ml or 50ml, see Note 8).

3. Centrifuge at $3220 \mathrm{~g}$ for $7 \mathrm{~min}$ at $4^{\circ} \mathrm{C}$ with a swinging bucket rotor (see Note 9).

4. Decant and discard the supernatant.

5. Add $1 \mathrm{ml}$ of $\mathrm{RNAlater}$ and store at $-80^{\circ} \mathrm{C}$ if not proceeding to extraction immediately.

6. Thaw samples preserved in RNAlater, or use fresh samples.

7. Centrifuge at $3220 \mathrm{~g}$ for $7 \mathrm{~min}$ at $4^{\circ} \mathrm{C}$ with a swinging bucket rotor.

8. Decant and discard the supernatant. 
9. Transfer all of the substrate and fungal mat into an autoclaved 2-ml screw-cap tube filled with $450 \mu \mathrm{L}$ of buffer RLT (QIAGEN) and $1.0 \mathrm{~mL}$ of $0.5 \mathrm{~mm}$ zirconia/silica beads (see Notes 10 - 11).

10. Briefly vortex to mix the beads, buffer, and sample (see Note 12).

11. Bead beat samples for one minute using Mini-Beadbeater-16.

12. Centrifuge at $13,000 \mathrm{~g}$ for $3 \mathrm{~min}$.

13. Transfer up to $650 \mu \mathrm{L}$ of lysate using gel loading pipet tips onto a QIAGEN RNeasy spin column.

14. Follow the protocol "Purification of Total RNA from Plant Cells and Tissues and Filamentous Fungi" from the RNeasy Mini Handbook (QIAGEN, see Note 13).

15. RNA yields can be measured using Qubit fluorometric quantitation, and RNA quality can be assessed using a TapeStation or Bioanalyzer (Agilent). For next-generation sequencing, we recommend using RNA with a RNA Integrity Number (RIN) > 9.0 (Figure 4).

\subsection{Genomic DNA extraction from fungal cultures grown on soluble substrates}

1. The preparation of genomic DNA from fungal cultures depends on the main carbon substrate used in the culture media. If media contain soluble substrates (e.g. cellobiose, glucose), then a gentle bead beating step is used to lyse the fungal cells [18]. Invert the culturing vessel (Hungate tubes or serum bottles) several times to break apart the plant substrate with fungal mat.

2. Transfer the culture media including the plant substrate into centrifuge tubes (15-ml or 50$\mathrm{ml})$.

3. Centrifuge at $3220 \mathrm{~g}$ for $7 \mathrm{~min}$ at $4^{\circ} \mathrm{C}$ with a swinging bucket rotor (see Note 9). 
4. Decant and discard the supernatant.

5. Follow the protocol included in the MO BIO PowerPlant Pro DNA Isolation Kit (see Note 14).

\subsection{Genomic DNA extraction from fungal cultures grown on plant substrates}

For media contains plant substrates (e.g. reed canary grass, corn stover), use a harsher bead beating step using the Mini-Beadbeater-16 is used for cell lysis, because plant substrates absorb a significant part of the bead beating force. In order to reduce background DNA introduced from rumen fluid, double clarified rumen fluid is recommended (Tables 1 and 2).

We have developed a method to extract RNA and DNA from the same sample based on the QIAGEN AllPrep DNA/RNA/miRNA Universal Kit. This may prove to be advantageous when the quantity of samples is limiting. Follow the second part of this simultaneous preparation of RNA and DNA.

1. Invert the culturing vessel (Hungate tubes or serum bottles) several times to break apart the plant substrate with fungal mat.

2. Transfer the culture media including the plant substrate into centrifuge tubes (15-ml or 50$\mathrm{ml}$, see Note 8).

3. Centrifuge at $3220 \mathrm{~g}$ for $20 \mathrm{~min}$ at $4^{\circ} \mathrm{C}$ with a swinging bucket rotor (see Note 9).

4. Decant and discard the supernatant.

5. Add $1 \mathrm{ml}$ of RNAlater and store at $-80^{\circ} \mathrm{C}$ if not proceeding to extraction immediately.

6. Thaw samples preserved in RNAlater, or use fresh samples.

7. Centrifuge at $3220 \mathrm{~g}$ for $20 \mathrm{~min}$ at $4^{\circ} \mathrm{C}$ with a swinging bucket rotor. 
8. Decant and discard the supernatant.

9. Transfer all of the substrate and fungal mat into an autoclaved 2-ml screw-cap tube filled with $500 \mu \mathrm{L}$ of buffer RLT Plus (QIAGEN) and $1.0 \mathrm{~mL}$ of $0.5 \mathrm{~mm}$ zirconia/silica beads (see Notes 10 - 11).

10. Briefly vortex to mix the beads, buffer, and sample (see Note 12).

11. Bead beat samples for 1.5 min using a Biospec Mini-Beadbeater-16.

12. Place sample tubes on ice for 1.5 min to lower the temperature.

13. Bead beat samples for another 1.5 min using a Biospec Mini-Beadbeater-16.

14. Centrifuge at $13,000 \mathrm{~g}$ for $3 \mathrm{~min}$.

15. Transfer up to $650 \mu \mathrm{L}$ of lysate using gel loading pipet tips onto a QIAGEN AllPrep DNA Mini spin column (see Notes 15-16).

16. Follow the protocol "Simultaneous Purification of Genomic DNA and Total RNA, including miRNA, from Cells" from the AllPrep ${ }^{\circledR}$ DNA/RNA/miRNA Universal handbook (QIAGEN).

17. DNA yields can be measured using Qubit fluorometric quantitation, and DNA quality can be assessed using a TapeStation or Bioanalyzer (Agilent). For next-generation sequencing, we recommend using DNA with a minimal degree of shearing (Figure 5). 


\section{Notes}

1. The "Medium C Minus" ("MC-") was developed for experiments that require measurements of media composition using high performance liquid chromatography (HPLC). With reduced concentrations of yeast extract (1/10), casitone (1/20), and rumen fluids (1/2) compared to Medium C, MC- contains lower concentrations of key primary metabolites, such as formate, acetate, and hence lower background signal on the HPLC. Both Medium C and MC- include rumen fluid and are undefined. A defined medium, Medium 2, is described by Lowe and colleagues [14].

2. Boiling for 20 minutes will remove approximately $200 \mathrm{ml}$ of water, so before heating the total volume of the medium solution should be $1200 \mathrm{ml}$ in order to reach a final volume of $1000 \mathrm{ml}$. After microwaving, the solution should be boiling and pink.

3. It is not necessary to purge with $\mathrm{CO}_{2}$ for a long time. Slow $\mathrm{CO}_{2}$ flow rate works better than high flow rate.

4. Alternatively, add a few chunks of dry ice into the solution.

5. Media are usually pink immediately after dispensing into Hungate tubes, but the pink color should disappear after autoclaving.

6. Before rolling the tubes under a cold water stream, avoiding small bubbles in the media will facilitate fungal colony identification.

7. This protocol is equally effective for fungal growth on soluble substrates (e.g. $5 \mathrm{~g} / \mathrm{L}$ glucose) and insoluble substrates (e.g. $0.1 \mathrm{~g}$ reed canary grass).

8. Depending on the purpose of the RNA analysis experiment, it may be necessary to perform this step in an anaerobic environment, such as an anaerobic chamber or a glove bag. 
9. Alternatively, the sample can be centrifuged for 1 hour at 20,000 g using a fixed angle rotor. This results in the separation of the less dense fungal mat on top of the plant substrate. This can be advantageous to reduce the amount of sample to process.

10. We find that a metal spatula with a flat end works best to transfer samples into 2-ml screwcap tubes for bead beating.

11. We found comparable results in RNA yield by liquid nitrogen grinding compared to bead beating for one minute using Mini-Beadbeater-16.

12. Vortex both orientations of the tube (cap down and cap up) in order to fully mix.

13. Perform "Optional On-Column DNA Digestion with the RNase-Free DNase Set" if performing RT-qPCR.

14. Use the Phenolic Separation Solution at step 1.

15. If the total volume of lysate from a sample was greater than $650 \mu \mathrm{L}$, repeat this step until all lysate has passed through the AllPrep DNA Mini spin column in order to maximize DNA yield. Generally the amount of DNA form fungal cultures $<50 \mathrm{ml}$ in volume is not sufficient to overload the AllPrep DNA Mini spin column.

16. Generally RNA yields are high enough from just $650 \mu \mathrm{L}$ of lysate that it is not necessary to save the flow-through from all of the lysate for RNA purification. 


\section{References}

1. Orpin CG (1977) The Occurrence of Chitin in the Cell Walls of the Rumen Organisms Neocallimastix frontalis, Piromonas communis and Sphaeromonas communis. Microbiology 99:215-218. doi: 10.1099/00221287-99-1-215

2. Mountfort DO, Orpin CG (1994) Anaerobic Fungi: Biology, Ecology, and Function. Marcel Dekker, Inc

3. Solomon KV, Haitjema CH, Thompson DA, O'Malley MA (2014) Extracting data from the muck: deriving biological insight from complex microbial communities and non-model organisms with next generation sequencing. Curr Opin Biotechnol 28:103-110. doi: 10.1016/j.copbio.2014.01.007

4. Solomon KV, Haitjema CH, Henske JK, et al (2016) Early-branching gut fungi possess a large, comprehensive array of biomass-degrading enzymes. Science aad1431. doi: $10.1126 /$ science.aad1431

5. Peng X, Gilmore SP, O’Malley MA (2016) Microbial communities for bioprocessing: lessons learned from nature. Curr Opin Chem Eng 14:103-109. doi:

10.1016/j.coche.2016.09.003

6. Gascoyne DJ, Theodorou MK (1988) Consecutive batch culture - A novel technique for the in vitro study of mixed microbial populations from the rumen. Anim Feed Sci Technol 21:183-189. doi: 10.1016/0377-8401(88)90099-5 
7. Haitjema CH, Solomon KV, Henske JK, et al (2014) Anaerobic gut fungi: Advances in isolation, culture, and cellulolytic enzyme discovery for biofuel production. Biotechnol Bioeng 111:1471-1482. doi: 10.1002/bit.25264

8. Hungate RE (1969) Chapter IV A Roll Tube Method for Cultivation of Strict Anaerobes. In: Ribbons JRN and DW (ed) Methods Microbiol. Academic Press, pp 117-132

9. Bryant MP (1972) Commentary on the Hungate technique for culture of anaerobic bacteria. Am J Clin Nutr 25:1324-1328.

10. Miller TL, Wolin MJ (1974) A Serum Bottle Modification of the Hungate Technique for Cultivating Obligate Anaerobes. Appl Microbiol 27:985-987.

11. Balch WE, Wolfe RS (1976) New approach to the cultivation of methanogenic bacteria: 2mercaptoethanesulfonic acid (HS-CoM)-dependent growth of Methanobacterium ruminantium in a pressureized atmosphere. Appl Environ Microbiol 32:781-791.

12. Orpin CG (1975) Studies on the Rumen Flagellate Neocallimastix frontalis. Microbiology 91:249-262. doi: 10.1099/00221287-91-2-249

13. Bauchop T, Mountfort DO (1981) Cellulose Fermentation by a Rumen Anaerobic Fungus in Both the Absence and the Presence of Rumen Methanogens. Appl Environ Microbiol 42:1103-1110.

14. Lowe SE, Theodorou MK, Trinci APJ, Hespell RB (1985) Growth of Anaerobic Rumen Fungi on Defined and Semi-defined Media Lacking Rumen Fluid. Microbiology 131:2225-2229. doi: $10.1099 / 00221287-131-9-2225$ 
15. Joblin KN (1981) Isolation, Enumeration, and Maintenance of Rumen Anaerobic Fungi in Roll Tubes. Appl Environ Microbiol 42:1119-1122.

16. Schoch CL, Seifert KA, Huhndorf S, et al (2012) Nuclear ribosomal internal transcribed spacer (ITS) region as a universal DNA barcode marker for Fungi. Proc Natl Acad Sci 109:6241-6246. doi: 10.1073/pnas.1117018109

17. Theodorou MK, Brookman J, Trinci APJ (2005) Anaerobic fungi. In: Makkar HPS, McSweeney CS (eds) Methods Gut Microb. Ecol. Rumin. Springer Netherlands, pp 55-66

18. Solomon K V., Henske JK, Theodorou MK, O’Malley MA (2016) Robust and effective methodologies for cryopreservation and DNA extraction from anaerobic gut fungi. Anaerobe 38:39-46. doi: 10.1016/j.anaerobe.2015.11.008

19. Theodorou MK, Davies DR, Nielsen BB, et al (1995) Determination of growth of anaerobic fungi on soluble and cellulosic substrates using a pressure transducer. Microbiology 141:671678. doi: 10.1099/13500872-141-3-671 
Table 1: Ingredients in Medium C

\begin{tabular}{|c|c|}
\hline Ingredients & Per $1000 \mathrm{ml}$ final volume \\
\hline Yeast Extract & $2.5 \mathrm{~g}$ \\
\hline Bacto Casitone & $10.0 \mathrm{~g}$ \\
\hline Sodium Bicarbonate & $6.0 \mathrm{~g}$ \\
\hline Mineral Solution I & $150 \mathrm{ml}$ \\
\hline Mineral Solution II & $150 \mathrm{ml}$ \\
\hline (Double*) Clarified Rumen Fluid & $150 \mathrm{ml}$ \\
\hline L-cysteine hydrochloride & $1.0 \mathrm{~g}$ \\
\hline Resazurin Stock Solution $(1 \mathrm{~g} / \mathrm{L})$ & $1.0 \mathrm{ml}$ \\
\hline Carbon Substrate (e.g. plant, cellubiose) & $1 \% \mathrm{w} / \mathrm{v}$ \\
\hline Optional: Agar (for roll tube preparation) & $10.0 \mathrm{~g}$ \\
\hline Optional: Glycerol (for cryo-preservation) & $150 \mathrm{ml}$ \\
\hline
\end{tabular}

\footnotetext{
*Clarified rumen fluid is sufficient for routine maintenance of fungal cultures, whereas double clarified rumen fluid is recommended for cultures from which DNA will be extracted.
} 
Table 2: Ingredients in "Medium C Minus" ("MC-", see Note 1)

\section{Ingredients}

Yeast Extract

Bacto Casitone

Sodium Bicarbonate

Mineral Solution I

Mineral Solution II

(Double*) Clarified Rumen Fluid

L-cysteine hydrochloride

Resazurin Stock Solution (1 g/L)

Carbon Substrate (e.g. plant, cellubiose)

Optional: Agar (for roll tube preparation)

Optional: Glycerol (for cryo-preservation)
Per 1000 ml final volume

$0.25 \mathrm{~g}$

$0.5 \mathrm{~g}$

$6.0 \mathrm{~g}$

$150 \mathrm{ml}$

$150 \mathrm{ml}$

$75 \mathrm{ml}$

$1.0 \mathrm{~g}$

$1.0 \mathrm{ml}$

$1 \% \mathrm{w} / \mathrm{V}$

$10.0 \mathrm{~g}$

$150 \mathrm{ml}$

*Clarified rumen fluid is sufficient for routine maintenance of fungal cultures, whereas double clarified rumen fluid is recommended for cultures from which DNA will be extracted. 


\section{Figures}

Figure 1. Media dispensing setup with a three-way gas manifold (clear-colored) to supply carbon dioxide simultaneously to the media bottle and two Hungate tubes to be filled. Also shown: a rack of Hungate tubes with pre-aliquoted plant material (center); two one-liter bottles of Medium C (left); serological pipets used for dispensing medium (center); black caps and grey butyl rubber septa for sealing Hungate tubes after medium is dispensed.

Figure 2. A pressure transducer assembly with digital display is used to measure the accumulation of gas pressure in the headspace of a fungal culture in a $60-\mathrm{ml}$ serum bottle.

Figure 3. A typical growth curve of anaerobic fungal culture Piromyces sp. (maintained on Medium C supplemented with reed canary grass) determined by monitoring the headspace pressure using a pressure transducer.

Figure 4. An example of high RNA quality isolated (RNA Integrity Number, RIN > 9.0) from anaerobic fungal cultures (upper panel), and an example of poor RNA quality $(\mathrm{RIN}<6.0)$ isolated from anaerobic fungal cultures (lower panel). Samples were measured on the Agilent 2200 TapeStation system (Agilent Technologies).

Figure 5. An example of high DNA quality isolated from fungal cultures (upper panel), and an example of poor, overly sheared DNA isolated from fungal cultures (lower panel). Samples were measured on the Agilent 2200 TapeStation system (Agilent Technologies). The genomic DNA ladders are marked by their sizes on the left, and fungal DNA samples are shown on the right. 